\title{
Effects of formal education for patients with inflammatory bowel disease: A randomized controlled trial
}

\author{
Barbara M Waters RN(EP) MN¹, Louise Jensen $\mathrm{RN} \mathrm{PhD}^{1}$, Richard N Fedorak MD FRCP ${ }^{2}$
}

BM Waters, L Jensen, RN Fedorak. Effects of formal education for patients with inflammatory bowel disease: A randomized controlled trial. Can J Gastroenterol 2005;19(4):235-244.

BACKGROUND: Patients with inflammatory bowel disease (IBD) suffer physical dysfunction and impaired quality of life (QOL), and need frequent health care. They often lack knowledge about their disease and desire more education. Educational interventions for other chronic diseases have demonstrated reduced health care use and increased knowledge, medication adherence and QOL.

METHOD: Sixty-nine participants were randomly assigned to formal IBD education and standard of care (pamphlets and ad hoc physician education) or standard of care alone. Assessment of IBD knowledge and QOL occurred at baseline, immediately posteducation and eight weeks posteducation. Participants documented medication adherence and health care use in diaries. Patient satisfaction was assessed at the end of the study.

RESULTS: The education group had higher knowledge scores $(\mathrm{P}=0.000)$, perceived knowledge ratings $(\mathrm{P}=0.01)$ and patient satisfaction $(\mathrm{P}=0.001)$. There was a lower rate of medication nonadherence and health care use for the education group, but the differences were not significant. QOL indices did not change. Significant correlations were found for increased health care use in patients with poorer medication adherence $(\mathrm{P}=0.01)$ and lower perceived health $(\mathrm{P}=0.05)$. CONCLUSION: Formal IBD patient education improves knowledge, perceived knowledge and patient satisfaction. Further study of long-term effects may better demonstrate potential benefits for QOL, medication adherence and health care use.

Key Words: Health care use; Inflammatory bowel disease; Medication adherence; Patient education; Patient satisfaction; Quality of life

Tflammatory bowel disease (IBD) is a chronic illness that has significant effects on the physical, psychological and social well being of the individual. The symptoms and complications of the disease can impair physical health considerably (1-3). Quality of life (QOL) suffers, particularly when the disease is active (4-8). The disease may affect employment, education and childbearing (9-14). Disease symptoms, impaired emotional and social functioning, disease severity and complications can lead to frequent health care use $(15,16)$. The multifaceted impact of the disease on the individual requires an integrated approach to disease management that incorporates biological and psychosocial aspects. The biopsychosocial

\section{Les effets d'une formation systématique des personnes atteintes d'une maladie inflammatoire de l'intestin : Un essai aléatoire et contrôlé}

HISTORIQUE : Les personnes atteintes d'une maladie inflammatoire de
l'intestin (MII) souffrent d'une dysfonction physique et d'une diminution
de leur qualité de vie (QDV), et ils ont besoin de soins de santé fréquents.
Ils connaissent mal leur maladie et veulent être plus informés. Les inter-
ventions pédagogiques à l'égard d'autres maladies chroniques ont démon-
tré une diminution des recours aux soins de santé et une augmentation des
connaissances, du respect de la pharmacologie et de la QDV.
MÉTHODOLOGIE : Soixante-neuf participants ont été aléatoirement
divisés entre une formation systématique sur les MII et des normes de dili-
gence (brochures et information ponctuelle transmise par le médecin) ou
des normes de diligence seulement. Les connaissances sur les MII et la
QDV ont été évaluées en début d'étude, dès après la formation et huit
semaines après la formation. Les patients ont documenté leur respect de la
pharmacologie et leur recours à des soins de santé dans un journal. La
satisfaction des patients a été évaluée en fin d'étude. RÉSULTATS : Le groupe de formation obtenait un meilleur pointage en matière de connaissances $(\mathrm{P}=0,000)$, de connaissances perçues $(\mathrm{P}=0,01)$ et de satisfaction des patients $(\mathrm{P}=0,001)$. Le taux de non-respect de la pharmacologie et de recours aux soins de santé était plus faible dans le groupe de formation, mais les différences n'étaient pas significatives. Les indices de QDV n'ont pas changé. Des corrélations significatives ont été découvertes pour ce qui est de l'accroissement du recours aux soins de santé chez les patients qui respectaient moins leur pharmacologie $(\mathrm{P}=0,01)$ et qui se percevaient en plus mauvaise santé $(\mathrm{P}=0,05)$.

CONCLUSION : La formation systématique des patients atteints d'une MII accroît les connaissances, les connaissances perçues et la satisfaction des patients. Une étude plus approfondie des effets à long terme pourrait mieux démontrer les bénéfices potentiels à l'égard de la QDV, du respect de la pharmacologie et du recours aux soins de santé.

approach includes medical therapy, psychosocial assessment and support, and patient education (17-19).

Patients have knowledge deficits about IBD (20-24). Surveys have consistently demonstrated patients' desire for more information about IBD, including outcomes, risk of cancer and new developments in disease management (25-31). Studies have revealed that patients are concerned about the impact of the disease, sexual intimacy, complications and body stigmata, and that those who experience greater symptoms report a lower level of health $(16,32)$. Finally, those that perceive they lack adequate information about their disease report poorer health (32).

${ }^{1}$ Faculty of Nursing; ${ }^{2}$ Division of Gastroenterology, Faculty of Medicine, University of Alberta, Edmonton, Alberta

Correspondence: Dr Louise Jensen, Faculty of Nursing, University of Alberta, 3rd Floor, Clinical Sciences Building, Edmonton, Alberta

T6G 2G3. Telephone 780-492-6759, fax 780-492-2551,e-mail louise.jensen@ualberta.ca

Received for publication July 29, 2004. Accepted January 3, 2005 
Structured educational interventions for other chronic illnesses have demonstrated decreased health care use and improved knowledge, psychosocial parameters, outcomes and adherence to medical regimens (33-40). Educational interventions for patients with IBD have consistently demonstrated improved knowledge, but no change in QOL indicators. Eaden et al (22) evaluated the efficacy of a video and pamphlet versus pamphlet alone as a method of educating ulcerative colitis patients about cancer risk and surveillance. Knowledge levels improved significantly with both interventions. Quan et al (41) reported improved knowledge levels after providing $3 \mathrm{~h}$ IBD workshops to members of the public. Schreiber et al (42) reported improved patient knowledge with a CD-ROM education program, but no change in QOL, though there was improvement in a disease-time trade off test. In a study of patients educated in disease self-management, Robinson et al (43) found improved adherence and lower health care use. Kennedy et al (44) developed an evidence-based guidebook on ulcerative colitis in collaboration with patients and health care professionals. Knowledge levels were significantly higher in the 132 patients in the group who received the guidebook compared with the 127 control patients. No change in QOL or anxiety levels was observed. Larsson et al (45) provided an eight-session education series to 26 IBD patients assessed to be at risk for high anxiety. Patients in the education program had higher satisfaction with educational information subsequently provided in the health care setting than did controls $(n=17)$ at six-month follow-up, but there was no change in anxiety levels or QOL. Borgaonkar et al (46) reported that QOL scores worsened for IBD patients who had been provided with educational pamphlets compared with controls. Although there have been various educational interventions studied for patients with IBD, there have been no structured, comprehensive education programs evaluated.

The purpose of the present study was to evaluate the effects of a formalized education program on patients with IBD. The researchers hypothesized that participants in the education program would demonstrate improved knowledge scores, perceived knowledge levels, QOL indices, perceived health status, medication adherence and patient satisfaction posteducation compared with those receiving the current standard of ad hoc education. It was further hypothesized that the education group would demonstrate a lower level of health care use.

\section{METHODS}

Over a four-week period, patients who were 17 years of age and older with a diagnosis of IBD confirmed by radiographic/endoscopic examination and/or histology/surgical pathology, and who lived within a $2 \mathrm{~h}$ drive of the University of Alberta Hospital (Edmonton, Alberta) were approached to participate in the study. Patients received information by mail with a follow-up telephone call or were approached during clinic visits. Inclusion criteria included the ability to attend the education program and fluency in written and spoken English. Those with short gut syndrome, disease limited to ulcerative proctitis, a proctocolectomy for ulcerative colitis, an ostomy, on total parenteral nutrition, or who underwent surgery during the study that required an ostomy, were excluded because these populations have unique health management issues. Consent was obtained, baseline data were collected, IBD literature and patient diaries were provided, and participants were randomized during an enrollment clinic visit.
Both the control and education groups received the current standard of care consisting of physician (primary care physician and gastroenterologist) visits, at the discretion of the physicians and patients, with physician-directed ad hoc teaching during visits and the presentation of printed educational literature. Printed educational literature included that provided by the Crohn's and Colitis Foundation of Canada and local gastroenterologists. The education group, in addition to standard of care, attended a $12 \mathrm{~h}$, structured education program provided in $3 \mathrm{~h}$ blocks over four consecutive weeks. To ensure no participants were disadvantaged, the control group was offered the full education program after the study data collection was completed.

The education program included general information about basic gut and immune system anatomy and physiology, explored the pathophysiology of IBD, and reviewed current and future therapy. Group discussion about disease management was tailored to address the identified worries and concerns of the subjects derived from baseline data. The principles of adult teaching and learning were applied, and a variety of teaching strategies were used to enhance learning and improve critical thinking skills. Remedial teaching was offered in the event of a missed class. Those participants who missed more than one class were removed from the data set, but continued to attend the education program. Data were collected at three time points: baseline (T1), immediately posteducation (T2) and eight weeks posteducation (T3) (Figure 1).

The education program was designed and provided by the Nurse Practitioner, Division of Gastroenterology, in $3 \mathrm{~h}$ blocks over four consecutive weeks. The first two classes focused on providing comprehensive information about the anatomy and physiology of the gut and immune system, ulcerative colitis and Crohn's disease pathology and resultant symptomology, and current therapeutic approaches. Commonly used medications were reviewed with a focus on the purpose of the medication, how it worked, the most common side effects and how to effectively manage them. The last two classes were dedicated to addressing topics identified as important from data analysis collected at baseline. The dietician from gastroenterology provided nutrition management education tailored to the diseases and their common complications. Additionally, the opportunity for individual dietary counselling was offered to interested participants. A surgeon presented information about surgical interventions, focusing on how surgical options are determined and the benefits of surgery. Following this presentation, a patient openly shared her experience living with an ostomy. Finally, the participants worked in small groups with facilitators discussing the psychological and interpersonal impacts of IBD, sexuality and childbearing, symptom management, stress reduction, cancer risks and surveillance, and medication management. The participants received copies of each presentation, a booklet on IBD medication and management, and an overview of the group discussion information.

Knowledge was assessed using two different, previously validated knowledge questionnaires: the Crohn's and Colitis Knowledge Questionnaire (CCKNOW) designed by Eaden et al (22), and the Knowledge Questionnaire (KQ) developed by Jones et al (23). The use of both questionnaires facilitated the examination of similar knowledge areas using different testing methods and provided a larger bank of questions. The Inflammatory Bowel Disease Questionnaire (IBDQ) and Rating Form for IBD Patient Concerns (RFIPC), both validated research tools, were used to assess QOL (4,5,8,16,47-48). These two instruments are complementary, providing a more comprehensive QOL assessment, because the IBDQ evaluates symptom and functional status and 


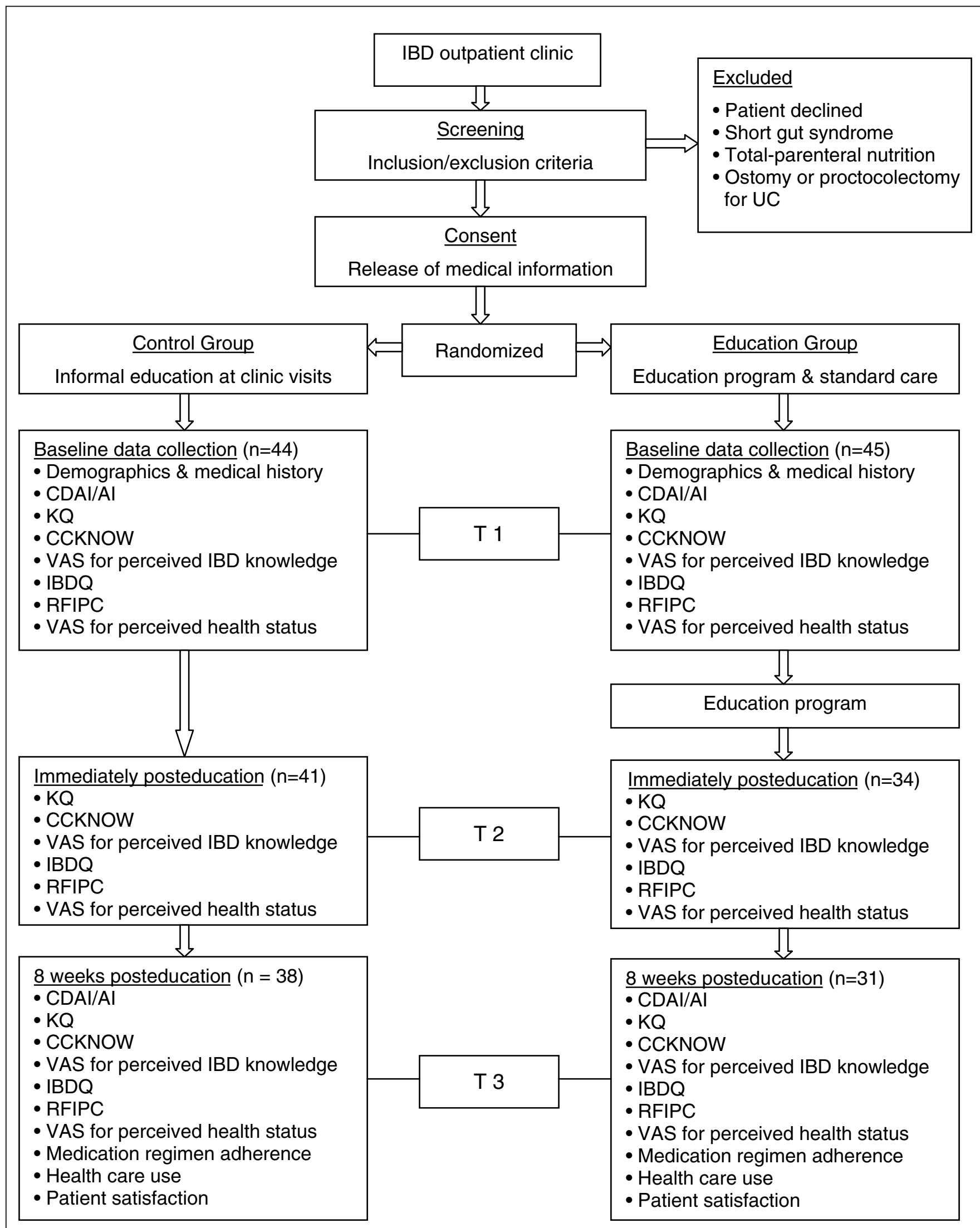

Figure 1) Study design. AI Activity Index (ulcerative colitis); CCKNOW Crohn's and Colitis Knowledge Questionnaire; CDAI Crohn's Disease AI; IBD Inflammatory bowel disease; IBDQ Inflammatory Bowel Disease Questionnaire; KQ Knowledge Questionnaire; RFIPC Rating form for inflammatory bowel disease patient concerns; T1 Baseline; T2 Immediately posteducation; T3 Eight weeks posteducation; UC Ulcerative colitis; VAS Visual analogue scale 
TABLE 1

Baseline comparison of participant characteristics

\begin{tabular}{lccc}
\hline & $\begin{array}{c}\text { Variable } \\
\mathbf{n = 4 4}\end{array}$ & $\begin{array}{c}\text { Education } \\
\mathbf{n = 4 5}\end{array}$ & $\mathbf{P}$ \\
\hline Mean age (years) & $45.0 \pm 13.5$ & $40.3 \pm 12.8$ & 0.094 \\
Male/Female & $22 / 22$ & $29 / 16$ & 0.122 \\
Disease characteristics & & & \\
Ulcerative colitis/Crohn's disease & $18 / 26$ & $14 / 31$ & 0.229 \\
Mean disease duration (years) & $13.4 \pm 9.84$ & $10.5 \pm 9.0$ & 0.156 \\
CDAl (mean score) & $188.3 \pm 117.1$ & $126.8 \pm 93.3$ & 0.064 \\
Activity index (mean score) & $114.1 \pm 37.8$ & $111.8 \pm 25.8$ & 0.876 \\
Medications, $\mathrm{n}$ (\%) & & & \\
Steroids & $9(20)$ & $3(7)$ & 0.123 \\
Azathioprine/6-mercaptopurine & $9(20)$ & $9(20)$ & 0.363 \\
Methotrexate & $1(2)$ & $1(2)$ & 0.689 \\
5-Aminosalicylate & $22(50)$ & $12(27)$ & 0.095 \\
Antibiotics (chronic therapy) & $3(7)$ & $3(7)$ & 0.539 \\
Monoclonal antibody & $3(7)$ & $4(9)$ & 0.360 \\
Osteoporosis therapy & $13(29)$ & $9(20)$ & 0.469 \\
Alternative therapy & $6(14)$ & $3(7)$ & 0.376 \\
Comorbid illness & $26(59)$ & $21(47)$ & 0.168 \\
Missed medications & $23(52)$ & $27(60)$ & 0.301 \\
Education opportunities, $\mathrm{n}$ (\%) & & & \\
Study participation & $16(36)$ & $22(49)$ & 0.164 \\
Prior education program & $6(14)$ & $8(18)$ & 0.404 \\
Internet use & $21(47)$ & $27(60)$ & 0.171 \\
CCFC member & $6(14)$ & $17(38)$ & 0.009 \\
CCFC support group & $9(20)$ & $11(24)$ & 0.422 \\
\hline
\end{tabular}

CDAI Crohn's Disease Activity Index; CCFC Crohn's and Colitis Foundation of Canada

the RFIPC addresses the psychosocial aspects of the disease. Perceived knowledge and health levels were assessed using colour-graded visual analogue scales (VAS) to which a 10-point scale was subsequently applied for quantification. Disease severity was assessed using the validated Crohn's Disease Activity Index (49-50) and Seo et al's Activity Index for ulcerative colitis (51-53). Participant satisfaction with medical care and the education program was assessed with Likert scale questionnaires developed by the researchers.

The effect of demographics (sex, age, level of education), disease (disease type, severity, duration, comorbid illness) and IBD education (previous IBD education programs, participation in IBD studies, Internet use, membership in the Crohn's and Colitis Foundation of Canada [CCFC] and attendance at the CCFC Support Group [CCFCSG]) on the outcome variables was also assessed. The effect of reading the provided IBD pamphlets on the control group IBD knowledge was also examined.

Descriptive statistics were used to describe participant characteristics, and differences between groups were assessed using repeated measures ANOVA, independent samples $t$ test, and $\chi^{2}$ as appropriate at the $\mathrm{P}=0.05$ level of significance. Relationships among variables were examined using Pearson's correlation coefficient.

\section{Recruitment}

\section{RESULTS}

Following a health record review for the selection of potential participants, an information letter about the study was sent to 259 patients. Successful personal contact by telephone was made with 167 of the mail recipients (64\%), of which 82 (49\%) were enrolled and nine $(6 \%)$ excluded based on the study criteria. Of the 12 patients approached while attending their gastroenterologist's clinic, seven (58\%) were enrolled. Reasons for declining participation in the study included other commitments $(53 \%)$, too far to travel $(20 \%)$, not interested (12\%), felt they did not need further education (6\%), too ill with comorbid disease (4\%), the classes were too late in the day $(2 \%)$ and lack of transportation (2\%). Of the 76 mail recipients (46\%) that declined participation, $63(83 \%)$ indicated that they would like to participate in an education program if offered again in the future.

Sixty-nine of the 89 enrolled participants (78\%) completed the study (education group: $n=31$; control group: $n=38$ ). Eleven education program participants were excluded from analysis when they missed more than one class. Reasons for missing classes included poor winter driving conditions $(n=2)$, conflicts with employment/postsecondary education $(n=6)$, and IBD exacerbation/complications $(n=3)$. Of the remaining 34 education group participants, three did not complete their questionnaires at T2 or T3. Six control group participants did not complete both T2 and T3 questionnaires. Those who did not complete all questionnaires were excluded from analysis. Reasons for incomplete questionnaires included illness $(n=2)$, death in the family $(n=1)$, lost in the mail $(n=3)$ and lost to follow-up $(n=3)$.

\section{Sample}

Of the 89 participants, there were 51 males and 38 females with an age range of 18 to 74 years. Educational preparation included junior high school $(n=6)$, high school $(n=35)$, college/ trade/technical school $(\mathrm{n}=27)$ and university $(\mathrm{n}=21)$. Comparison of the control and education groups revealed no statistically significant differences on demographic variables. Disease severity was similar in both groups and did not change over the course of the study. There was no difference between groups for IBD study participation, prior IBD education, Internet use or CCFCSG attendance. More participants in the education group $(n=17,38 \%)$ than in the control group $(n=6$, $13 \%)$ had active or former membership in the CCFC $\left(\chi^{2}=6.77, \mathrm{P}=0.009\right)$. This difference had no effect on study outcomes (Table 1 ).

\section{Knowledge}

The KQ and CCKNOW assess knowledge levels in five topic categories: diet, gut anatomy and physiology, general IBD knowledge, complications and medications. Baseline mean $\mathrm{KQ}$ scores were similar for the control and education group (17.24/37 and $17.13 / 37 ; 46 \%$, respectively) and there was no significant difference between CCKNOW scores 10/24 (41\%) and 12/24 (50\%), respectively (Table 2). Knowledge levels improved over the course of the study (KQ: $\mathrm{F}=96.71, \mathrm{P}=0.000$; CCKNOW: $\mathrm{F}=118.87, \mathrm{P}=0.000$ ); however, the education group total mean scores were higher at $\mathrm{T} 2$ and $\mathrm{T} 3$ (KQ: $\mathrm{F}=20.16, \mathrm{P}=0.000$; CCKNOW: $\mathrm{F}=14.22, \mathrm{P}=0.000$ ) (Figure 2). No significant difference was found at baseline or over time when those in the control group $(n=25,65 \%)$ who read the provided IBD literature were compared with those who did not $(n=13,34 \%)$.

Higher baseline knowledge scores were found for those who received prior formal IBD education (KQ: $t=2.19, \mathrm{P}=0.031$; CCKNOW: $t=2.91, \mathrm{P}=0.005$ ) or were members of the CCFC 
TABLE 2

Comparison of mean knowledge scores

\begin{tabular}{|c|c|c|c|c|c|c|c|}
\hline & \multicolumn{3}{|c|}{ Control group $(n=38)$} & \multicolumn{3}{|c|}{ Education group $(n=31)$} & \multirow[b]{2}{*}{$\mathbf{P}$} \\
\hline & $\overline{\mathrm{T} 1}$ & T2 & $\overline{\mathrm{T3}}$ & $\overline{T 1}$ & T2 & $\overline{T 3}$ & \\
\hline \multicolumn{8}{|l|}{ Knowledge Questionnaire } \\
\hline Total correct $(37)^{*}$ & $17.24 \pm 5.81$ & $20.84 \pm 6.34$ & $21.47 \pm 6.81$ & $17.13 \pm 7.00$ & $27.77 \pm 3.23$ & $27.19 \pm 3.03$ & 0.000 \\
\hline $\operatorname{Diet}(4)$ & $1.61 \pm 0.97$ & $2.16 \pm 1.13$ & $2.34 \pm 2.58$ & $1.68 \pm 1.35$ & $2.81 \pm 1.05$ & $2.71 \pm 1.04$ & 0.380 \\
\hline$A \& P(3)$ & $1.39 \pm 0.92$ & $1.47 \pm 0.98$ & $1.79 \pm 1.79$ & $1.32 \pm 0.87$ & $1.81 \pm 0.75$ & $1.71 \pm 0.69$ & 0.317 \\
\hline Disease knowledge (11) & $5.76 \pm 2.59$ & $6.50 \pm 2.55$ & $6.79 \pm 2.56$ & $5.52 \pm 1.98$ & $9.00 \pm 1.37$ & $8.68 \pm 1.28$ & 0.000 \\
\hline \multicolumn{8}{|l|}{ CCKNOW } \\
\hline Total correct (24) & $9.79 \pm 4.94$ & $13.34 \pm 5.66$ & $13.84 \pm 4.86$ & $11.58 \pm 5.64$ & $19.29 \pm 3.30$ & $19.52 \pm 2.55$ & 0.000 \\
\hline $\operatorname{Diet}(2)$ & $1.34 \pm 0.67$ & $1.42 \pm 0.72$ & $1.66 \pm 0.58$ & $1.23 \pm 0.72$ & $1.90 \pm 0.30$ & $1.94 \pm 0.25$ & 0.001 \\
\hline$A \& P(5)$ & $1.84 \pm 1.31$ & $2.68 \pm 1.61$ & $2.74 \pm 1.59$ & $2.55 \pm 1.67$ & $4.42 \pm 0.92$ & $4.32 \pm 1.08$ & 0.333 \\
\hline Complications (6) & $2.32 \pm 1.56$ & $3.32 \pm 1.69$ & $3.39 \pm 1.35$ & $2.84 \pm 1.83$ & $4.58 \pm 1.29$ & $4.90 \pm 0.94$ & 0.013 \\
\hline
\end{tabular}

*Number of questions. A\&P Gut anatomy and physiology; CCKNOW Crohn's and Colitis Knowledge Questionnaire; T1 Baseline; T2 Immediately posteducation; T3 Eight weeks posteducation

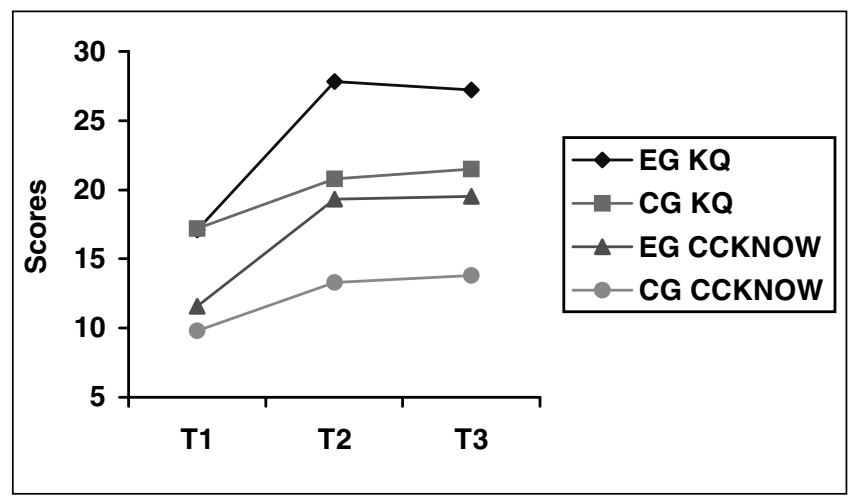

Figure 2) Comparison of mean total knowledge scores. CCKNOW Crohn's and Colitis Knowledge Questionnaire; CG Control group; EG Education group; KQ Knowledge Questionnaire; T1 Baseline; T2 Immediately posteducation; T3 Eight weeks posteducation

(KQ: $t=3.78, \mathrm{P}=0.000$; CCKNOW: $t=3.09, \mathrm{P}=0.000$ ); however, the differences did not persist over time. Attendees of the CCFCSG had higher scores at baseline (KQ: $t=3.55, \mathrm{P}=0.001$; CCKNOW: $t=2.91, \mathrm{P}=0.005)$, a difference that persisted over the course of the study (KQ: $\mathrm{F}=3.55, \mathrm{P}=0.048$; CCKNOW: $\mathrm{F}=6.62, \mathrm{P}=0.005$ ).

Perceived knowledge levels as assessed by VAS increased in both groups at $\mathrm{T} 2$ and $\mathrm{T} 3(\mathrm{~F}=31.53, \mathrm{P}=0.000)$, but were higher for the education group $(\mathrm{F}=5.80, \mathrm{P}=0.01)$ (Figure 3). Higher perceived knowledge ratings were found for CCFC members $(t=4.01, \mathrm{P}=0.000)$ and CCFCSG participants $(t=2.08$, $\mathrm{P}=0.04$ ), but the differences did not persist after the education program.

\section{QOL}

The IBDQ has 32 questions in which patients rate their physical, social and emotional symptom experience over the previous two weeks on a scale of 1 to 7 , with 1 meaning all of the time and 7 meaning none of the time. Low scores indicate more severe disease activity and/or higher emotional and social

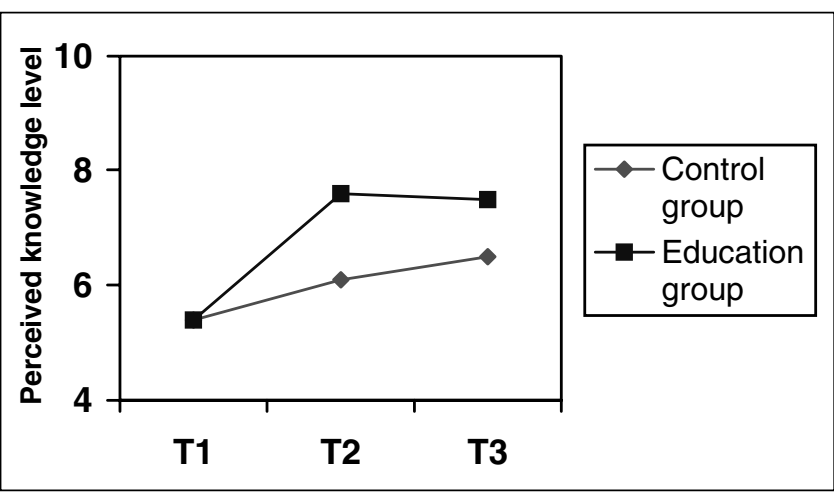

Figure 3) Comparison of perceived knowledge level. T1 Baseline; T2 Immediately posteducation; T3 Eight weeks posteducation

dysfunction. No difference was found for IBDQ total scores between groups at baseline, T2 or T3. Increased disease severity was associated with worse physical symptoms and greater psychosocial dysfunction $(\mathrm{P}=0.01)$. The baseline mean IBDQ scores of participants with quiescent Crohn's disease was elevated at 174.35 (range 97 to 211) and 186.76 (range 152 to 214) for those with ulcerative colitis. Those whose education did not continue beyond junior high school had lower mean baseline scores $(\mathrm{F}=6.67, \mathrm{P}=0.000)$, a difference that persisted over time $(\mathrm{F}=1.99, \mathrm{P}=0.021)$. This group also had significantly higher scores for bowel symptoms at baseline $(\mathrm{F}=3.51$, $\mathrm{P}=0.051)$ and over time $(\mathrm{F}=2.28, \mathrm{P}=0.045)$. Higher perceived knowledge ratings were associated with higher IBDQ scores $(\mathrm{P}=0.05)$; however, higher knowledge scores were not.

The RFIPC asks patients to rate, on a scale of 0 to 100 , the degree of worry and concern they experience in relation to 25 specific questions that are divided into four indices: impact of disease (13 questions); body stigma (two questions); sexual intimacy (three questions); and complications (four questions). Additionally, concern about being treated differently, 
transmitting the disease to others and the ability to bear children are assessed individually.

No differences were found between the education and control groups for mean total RFIPC scores over the course of the study $(\mathrm{F}=1.27, \mathrm{P}=0.285)$, nor were there differences for the four index scores. A difference was found between groups for concern about "being treated differently" $(\mathrm{F}=4.02, \mathrm{P}=0.02)$. Those with only junior high school-level education had greater concern about the impact of disease $(\mathrm{F}=4.43, \mathrm{P}=0.006)$, body stigma $(\mathrm{F}=3.58, \mathrm{P}=0.017)$, sexual intimacy $(\mathrm{F}=4.40$, $\mathrm{P}=0.006)$, being treated differently $(\mathrm{F}=5.81, \mathrm{P}=0.001)$ and a higher mean total score $(\mathrm{F}=4.70, \mathrm{P}=0.004)$ at baseline, but the differences did not persist over time. Perceived knowledge levels and knowledge scores did not correlate with RFIPC total mean scores.

Participants rated their health from poor (0) to excellent (10) on the perceived health VAS. The mean baseline rating for all participants was 6.18 (range 1.75 to 10 ) and improved over the course of the study for both groups $(\mathrm{F}=7.94, \mathrm{P}=0.001)$. The education group had higher perceived health ratings at $\mathrm{T} 2$ and $\mathrm{T} 3$, but the difference did not reach statistical significance $(\mathrm{F}=2.34, \mathrm{P}=0.106)$. Although there was no relationship at baseline, improved perceived health was associated with higher perceived knowledge at T2 and T3 ( $\mathrm{P}=0.01)$; however, no correlation was found between perceived health and knowledge scores. Those with higher perceived health ratings had less dysfunction on the IBDQ $(\mathrm{P}=0.01)$ and a lower rating for worries and concerns on the RFIPC $(\mathrm{P}=0.01)$. High Crohn's Disease Activity Index scores correlated with lower perceived health $(\mathrm{P}=0.05)$, but this was not a consistent finding with the Activity Index (for ulcerative colitis). Those with Crohn's disease had a lower perceived health status than those with ulcerative colitis at baseline $(t=2.36, \mathrm{P}=0.021)$, but the difference did not persist over time.

\section{Medication adherence}

Medication adherence was assessed by three methods: survey at baseline; a set of questions on the Patient Satisfaction Questionnaire; and participant self-report. During enrollment, each participant was asked the question "Do you ever miss taking your medications?" Forty-eight participants (54\%) responded in the affirmative. The Patient Satisfaction Questionnaire asked participants to rate their agreement to questions about making errors taking medications, missing scheduled medications and stopping medications independently due to side effects. Fifty-four per cent of participants had scores above the median, indicating that they experienced difficulty with medication regimen adherence.

Over the course of the study, 72 participants maintained a diary in which they recorded an entry for each instance of a missed medication and the reason for the occurrence. A total of 166 incidents of missed medications with a mean of 2.31 incidents per participant were reported. Although the education group had a lower rate of missed medications $(M=0.91)$ than the control group $(M=3.43)$, the difference did not reach significance. The education group also demonstrated a trend suggesting a lower rate of nonadherence over the three months ( $\mathrm{T} 1: \mathrm{M}=0.34 ; \mathrm{T} 2: \mathrm{M}=0.32 ; \mathrm{T} 3: \mathrm{M}=0.25$ ). The four most commonly cited reasons for missing medication was "forgetting", followed by "leaving medications at home", "prescription ran out" and "side effects". Other reasons provided by participants included "missed meals, so did not take medications" and "slept in". Females missed taking medications more often than males $(t=-1.89, \mathrm{P}=0.036)$, attendees of the CCFCSG demonstrated greater medication regimen adherence $(t=-1.29, \mathrm{P}=0.018)$, and Internet users had a higher rate of nonadherence than nonusers $(t=2.04, \mathrm{P}=0.048)$.

\section{Health care use}

Seventy-two participants maintained a record of physician visits and hospital admissions related to IBD and the associated complications. Forty-nine physician visits, 16 for symptom assessment and 33 for follow-up, were reported. Participants initiated 18 of the visits, and the balance $(n=31)$ were physicianinitiated. There were four emergency and five inpatient admissions. Hospitals stays ranged from two to seven days for a total of 25 inpatient days. Six of the admissions were for disease exacerbations; the rest were for IBD-related complications (nephrolithiasis, fistulotomy and fistula). An audit of 13 (18\%) of the records revealed $100 \%$ accuracy when compared with physician and hospital health records.

Although the difference was not significant $(t=1.06$, $\mathrm{P}=0.294)$, the education group had a lower rate of health care use $(M=0.63)$ than the control group $(M=0.95)$. The difference may be attributed to the lower rate of physician visits of the education group $(\mathrm{M}=0.53)$ than the control group $(\mathrm{M}=0.80)$. Those who had attended a formal education program before the study had significantly lower health care use $(t=-1.23, \mathrm{P}=0.03)$. Higher disease severity scores correlated with more frequent physician visits $(\mathrm{P}=0.05)$. Similarly, those who reported missing medications in their diaries had a higher rate of physician visits $(\mathrm{P}=0.01)$. Perceived health, perceived knowledge, knowledge scores and QOL indices had no association with health care use.

\section{Participant satisfaction}

Participant satisfaction with medical care and the education program was assessed with questionnaires using a Likert scale with 1 being "strongly agree" and 4 being "strongly disagree". Additionally, space for comments was provided for each question. Satisfaction with medical care assessed the effectiveness of education through information sharing (four items), whether information needs were met (four items), the adequacy of medication education (four items), and understanding of provided information (two items). Several of the survey questions specifically addressed physician education of participants within the context of the assigned categories. Separate analysis of these items was included because doctors are primary care providers and the most significant professional source of medical information (four items).

The mean score for patient satisfaction with IBD medical care was 41.31 (range 18 to 52). The mean satisfaction score for physician education was 12.86 (range 4 to 16). Control group total satisfaction scores were significantly lower for effectiveness of education through information sharing $(t=-3.51$, $\mathrm{P}=0.001)$, meeting information needs $(t=-3.13, \mathrm{P}=0.001)$, and total satisfaction $(t=-3.54, \mathrm{P}=0.001)$ (Table 3$)$. Higher satisfaction scores correlated with higher perceived knowledge $(\mathrm{P}=0.01)$, actual knowledge scores $(\mathrm{P}=0.01)$, higher IBDQ scores $(\mathrm{P}=0.05)$ and lower RFIPC ratings $(\mathrm{P}=0.01)$.

Participant comments reflected a desire for more information, the need for in-depth understandable literature, and assistance in understanding written information. Ten participants in the control group indicated a lack of confidence in 
their understanding of the disease and how to manage medications, symptoms and psychosocial effects. Comments also indicated that health care providers were inconsistent in providing medication education. Although there was some frustration expressed with the lack of time for discussion during clinic visits, participants provided favourable comments about the education efforts of their physicians.

Evaluation of the education program focused on satisfaction with improved disease understanding and the presentation methods. The mean satisfaction score for the education program was 49.97 (range 33 to 56). The mean score for improved disease understanding was 31.44 (range 19 to 36) and the mean score for program presentation was 18.81 (range 14 to 20). Those with ulcerative colitis were significantly more satisfied with the education program than those with Crohn's disease $(t=2.34, \mathrm{P}=0.005)$. Participant comments expressed general satisfaction with the program, indicating an increased understanding of the disease and management, but some comments indicated a need for more time and information on managing the psychosocial aspects of the disease.

\section{DISCUSSION}

Patients' desire for more information and having low knowledge scores is well documented (20-31). The present study not only underscored patients' limited IBD knowledge and desire for better education, but also identified the importance of education that is flexible and easy to access. Barriers to access included the distance from the centre where the education program was provided, the timing of the classes, illness and lack of transportation. When developing educational strategies for patients with IBD, careful consideration should be given to the potential barriers to access.

The significantly improved knowledge scores in the education group clearly supports the value of formal education for the IBD population and is in keeping with the reported benefits of formal education for other chronic disease populations (33-40). Further, the study supports the findings of Zernicke and Henderson (54) that formal education is superior to ad hoc patient teaching. Devine et al (36) reported a diminished effect size in knowledge levels over time in their metaanalysis of educational interventions, and Eaden et al (22) noted lower knowledge scores one month posteducation for ulcerative colitis patients. Kennedy et al (44) found that knowledge scores were similar nine months after providing an education handbook. Similarly, in the present study, the posteducation knowledge scores were unchanged over time and may reflect the intensive, comprehensive nature of the education program and availability of reference material. The previously reported benefit of membership in lay IBD organizations in enhancing patient knowledge was also evident, because those with prior education had higher baseline knowledge scores $(22-23)$.

Although the education group had higher knowledge scores, the control group also demonstrated improved knowledge scores over the course of the study. This improvement may have been due to some participants reading the provided pamphlets, test familiarity or information seeking prompted by the test questions. There was no difference between control group readers and nonreaders. In a meta-analysis that included assessment of education with pamphlets alone, Theis and Johnson (55) reported only a small effect size. The small sample size of readers in this study may have been too small to
TABLE 3

Comparison of mean patient satisfaction scores with mean medical care scores

\begin{tabular}{lrrrr}
\hline & $\begin{array}{c}\text { Control group } \\
(\mathbf{n}=\mathbf{3 8})\end{array}$ & $\begin{array}{c}\text { Education group } \\
(\mathbf{n}=\mathbf{3 1})\end{array}$ & $\boldsymbol{t}$ & $\mathbf{P}$ \\
\hline Total satisfaction & $38.60 \pm 8.63$ & $44.81 \pm 5.76$ & -3.45 & 0.001 \\
Disease understanding & $11.55 \pm 2.51$ & $13.48 \pm 2.00$ & -3.51 & 0.001 \\
Information needs met & $12.10 \pm 3.36$ & $14.16 \pm 1.68$ & -3.13 & 0.001 \\
Medication education & $9.23 \pm 3.19$ & $10.35 \pm 2.20$ & -1.68 & 0.097 \\
Medication understanding & $6.25 \pm 1.50$ & $6.87 \pm 1.20$ & -1.88 & 0.064 \\
\hline
\end{tabular}

appreciate any improvement in knowledge scores. A second consideration is the level of understanding of the provided written material. Estey et al (56) noted that patient education literature should be written at a grade 8 level or less to enhance understanding. With the exception of a handout on medication management, the provided pamphlets were written at or above a grade 10 level. Finally, the provided pamphlets are the standard information given to all patients; these pamphlets may have been previously read, thus limiting the learning of new information.

The education program improved perceived knowledge scores. Those with higher knowledge scores also rated their knowledge levels higher. Moser et al (32) reported that those with higher perceived knowledge had fewer worries and concerns, but this was not the case in the present study. There was no correlation between perceived knowledge levels and the RFIPC; however, the sample size may have been insufficient to demonstrate a difference. Higher perceived knowledge correlated with higher IBDQ scores and greater patient satisfaction. These findings suggest that having greater confidence in one's disease knowledge has some positive psychological benefits.

Meta-analyses of chronic disease educational interventions have found small-to-moderate positive effect sizes on QOL outcomes (33-40). This has not been demonstrated thus far in the IBD population; however, Schreiber et al (42) noted an improvement in a disease-time trade off test although there was no change in QOL scores posteducation (42-46). No improvement in QOL scores for the education group was found on either the IBDQ or RFIPC. Increased anxiety after education interventions of up to $20 \%$ of participants has been reported $(57,58)$. Verma et al $(57)$ suggested that higher knowledge levels may raise anxiety and have a deleterious effect on QOL indices, but this study was limited by a crosssectional design and use of unvalidated instruments. Kennedy et al (44) noted a trend to improved QOL scores nine months posteducation and suggested that the study time frame was too short to appreciate the full benefit of the intervention. The effect of possible heightened anxiety from patient education on QOL indices may be secondary to the immediacy of the testing to the intervention. Examination of QOL indices more remotely from the intervention may ameliorate any anxiety effect and demonstrate the positive psychological benefits reported elsewhere in the chronic disease literature. A further consideration is that the small sample sizes in these studies are inadequate to assess the multiple, complex interactive factors that affect QOL assessment.

Participants with increased disease severity demonstrated greater psychosocial dysfunction, supporting the well-established association between disease severity and psychosocial dysfunction $(6-7,16)$. A higher level of psychological dysfunction in 
IBD patients in remission than in normal controls has been reported $(7,47)$. Likewise, in the present study, the mean IBDQ scores of those with quiescent disease, although lower than those with active disease, were indicative of some psychological dysfunction.

Although the differences did not persist over time, those whose education did not extend beyond junior high school had significantly poorer RFIPC scores. Similarly, Drossman et al (5) reported lower education levels correlated with higher anxiety levels. Those with lower education levels may have more difficulty comprehending disease information and have less well-developed coping skills, leading to greater anxiety. The comprehensive IBD and self-management education provided may have benefited those with lesser education by decreasing their disease-related anxiety.

Perceived health did not improve with education. Disease severity had a deleterious effect on perceived health status, and Crohn's disease patients, who had more severe disease overall, had significantly lower ratings than those with ulcerative colitis. Drossman et al (16) attributed disease severity as contributing to a lower sense of well-being in Crohn's disease patients. Perceived heath ratings also correlated significantly with IBDQ and RFIPC scores at all time points, with higher perceived health status being associated with lower psychological dysfunction. The consistent correlation of the VAS for perceived health with the more complex QOL instrument raises the possibility that it may prove to be a quick, efficient tool for use in the clinical setting to help identify patients who are experiencing psychosocial distress.

Response to the survey questions about nonadherence revealed that over $50 \%$ of participants missed medications; however, only $29 \%$ actually reported missing medications in their diary. The difference in reporting may reflect the short duration of the diary (the survey question covered a longer timeline). In meta-analyses of education interventions, improved medication adherence has been found (34-36,40). Schreiber et al (42) found improved medication adherence in a group of IBD patients provided education by CD-ROM. Longer follow-up with a larger sample size may better demonstrate the possible benefits of education to medication adherence.

Analysis of demographic variables revealed that females missed medications more often; however, the reasons for the difference were not clear. Internet users also had a higher rate of nonadherence. Dissatisfaction with current treatment modalities may lead to lower medication adherence and the search for alternative methods of managing the disease. CCFCSG attendees had a significantly higher rate of adherence, possibly reflecting a greater awareness of disease management and the benefits of ongoing disease education that membership provides.

Meta-analyses have demonstrated that education interventions reduce health care use $(38,60)$. Robinson et al (43) reported decreased health care use in IBD patients who had been educated in disease self-management. In this study, the education group demonstrated a trend toward lower health care use. Significantly lower use was found for those who had received previous formal education, suggesting a long-term benefit of education in reducing health care use. Medication nonadherence was associated with higher health care use; specifically, with more frequent physician visits. Therapeutic management of IBD requires long-term maintenance therapy, and lapses in medication adherence predispose patients to disease exacerbations and consequent need for physician follow-up. Further, medication side effects leading to nonadherence may contribute to increased physician visits.

Drossman et al $(5,16)$ reported that poorer psychosocial function, weight loss, and steroid use were associated with greater health care use and that perceived well being was the most significant factor affecting physicians visits. De Boer et al (15) reported that disease activity, poor emotional functioning, impaired social function and disease burden were predictive of increased health care use. In this study, only disease severity correlated with increased health care use, specifically physician visits.

In the present study, the health care satisfaction ratings were relatively high for both groups; however, the education group reported a significantly greater degree of satisfaction with disease understanding, meeting of information needs, and overall satisfaction. Comments provided by control group participants on the Patient Satisfaction Survey indicated a lack of confidence in disease management. Increased knowledge of the disease and approach to medical management may contribute to greater understanding of the prescribed therapeutic regimen, help patients to identify concerns that need to be addressed by medical staff, and provide a greater sense of confidence when approaching health professionals.

Higher patient satisfaction with medical care was associated with lower psychosocial dysfunction. Emotional and social distress related to the disease may contribute to an overall lower level of satisfaction that is consequently reflected in the satisfaction with medical care. Patient comments on the survey indicated frustration with the lack of time to address concerns with health care providers. Patient interactions with health care professionals are often limited to short clinic visits that tend to focus on physical symptoms and medical management.

Satisfaction with the education program was high. Participants were very satisfied with their increased understanding of the disease and the program presentation methods. Ulcerative colitis patients were more satisfied with the program than those with Crohn's disease. Most patient education literature provides broad information about IBD, often focusing more specifically on Crohn's disease due to the complex presentations of this disease entity. The education program clearly delineated the differences in the disease presentations, symptoms, medical management, and self-management between Crohn's disease and ulcerative colitis. Much of the information provided may have been new to those with ulcerative colitis, and the specific focus on their disease may have resulted in a greater sense of satisfaction with the program.

Overall, participant comments on the education program were positive. Several participants expressed a desire for more information and time spent on the psychosocial aspects of the disease. From the educator's perspective, shorter classes over six to eight weeks and a smaller class size would have facilitated a more intimate sharing experience and may have been less exhausting for participants.

\section{CONCLUSION}

The formal IBD patient education program improved knowledge, perceived knowledge and patient satisfaction. Positive trends toward greater medication adherence and lower health care use were demonstrated. Comprehensive chronic disease care includes a structured education component. The current 
practice of relying on ad hoc, informal teaching during clinic visits and reliance on written materials needs to be reviewed. Innovative education programs that are flexible and accessible to those with IBD need to be developed. Further, programs should include a component of ongoing education.
Technology such as the Internet, teleconferencing or interactive, computer-based education may provide an effective means of facilitating ongoing education and overcoming some of the barriers of time, geography, illness and transportation.

\section{REFERENCES}

1. Ballinger A. Epidemiology, presentation, natural history and prognosis of inflammatory bowel disease. In: Rampton D, ed. Inflammatory Bowel Disease: Clinical Diagnosis and Management. London: Martin Dunitz, 2000:59-70.

2. Lashner BA. Clinical features, laboratory findings, and course of Crohn's disease. In: Kirsner JB, ed. Inflammatory Bowel Disease. Philadelphia: WB Saunders, 2000:305-14.

3. Miner PB. Clinical features, course, laboratory findings, and complications in ulcerative colitis. In: Kirsner JB, ed. Inflammatory Bowel Disease. Philadelphia: WB Saunders, 2000:299-304.

4. Mitchell A, Guyatt G, Singer J, et al. Quality of life in patients with inflammatory bowel disease. J Clin Gastroenterol 1988; 10:306-10.

5. Drossman DA, Leserman J, Li ZM, Mitchell CM, Zagami EA, Patrick DL. The rating form of IBD patient concerns: A new measure of health status. Psychosom Med 1991;53:701-12.

6. Turnbull GK, Vallis TM. Quality of life in inflammatory bowel disease: The interaction of disease activity with psychosocial function. Am J Gastroenterol 1995;90:1450-4.

7. Martin A, Leone L, Fries W, Naccarato R. Quality of life in inflammatory bowel disease. Ital J Gastroenterol 1995;27:450-4.

8. Guyatt G, Mitchell A, Irvine EJ, et al. A new measure of health status for clinical trials in inflammatory bowel disease. Gastroenterology 1989;96:804-10.

9. Mayberry JF. Impact of inflammatory bowel disease in educational achievements and work prospects. J Pediatr Gastroenterol Nutr 1999;28:S34-6

10. Mayberry MK, Probert C, Srivastava E, Rhodes J, Mayberry JF. Perceived discrimination in education and employment by people with Crohn's disease: A case control study of education achievement and employment. Gut 1992;33:312-4.

11. Burakoff R. Fertility and pregnancy in inflammatory bowel disease. In: Kirsner JB, ed. Inflammatory Bowel Disease. Philadelphia: WB Saunders, 2000:372-8.

12. Hanan IM. Inflammatory bowel disease in the pregnant woman. Compr Ther 1998;24:409-14.

13. Clearfield HR, Herrero C. Inflammatory bowel disease in pregnancy. Pract Gastroenterol 1998;22:21-31.

14. Rubin SD, Korelitz BI. Considerations regarding fertility and pregnancy in the management of inflammatory bowel disease. Pract Gastroenterol 1996;20:12-23.

15. de Boer AG, Sprangers MA, Bartelsman JF, de Haes HC. Predictors of health care utilization in patients with inflammatory bowel disease: A longitudinal study. Eur J Gastroenterol Hepatol 1998;10:783-9.

16. Drossman DA, Leserman J, Mitchell CM, Li ZM, Zagami EA, Patrick DL. Health status and health care use in persons with inflammatory bowel disease. A national sample. Dig Dis Sci 1991;36:1746-55.

17. Corazziari E. The new century challenges for chronic gastrointestinal disorders. Gastroenterol Int 2000;13:1-6.

18. Drossman DA. Presidential address: Gastrointestinal illness and the biopsychosocial model. Psychosom Med 1998;60:258-67.

19. Talal AH, Drossman DA. Psychosocial factors in inflammatory bowel disease. Gastroenterol Clin North Am 1995;24:699-716.

20. Marshall JG. The information needs of patients with Crohn's disease. Patient Couns Health Educ 1979;1:142-5.

21. O'Sullivan M, O'Morain C. Patient knowledge in inflammatory bowel disease. Am J Gastroenterol 2000;95:2128-9. (Lett)

22. Eaden JA, Abrams K, Mayberry JF. The Crohn's and Colitis Knowledge Score: A test for measuring patient knowledge in inflammatory bowel disease. Am J Gastroenterol 1999;94:3560-6.

23. Jones SC, Gallacher B, Lobo AJ, Axon AT. A patient knowledge questionnaire in inflammatory bowel disease. J Clin Gastroenterol 1993;17:21-4.

24. Ryan WR, Ley C, Allan RN, Keighley MR. Patients with Crohn's disease are unaware of the risks that smoking has on their disease. J Gastrointest Surg 2003;7:706-11.

25. Kennedy ED, Blair JE, Ready R, et al. Patients' perceptions of their participation in a clinical trial for postoperative Crohn's disease. Can J Gastroenterol 1998;12:287-91.

26. Mansfield JC, Tanner AR, Bramble MG. Information for patients about inflammatory bowel disease. J R Coll Physicians Lond 1997;31:184-7.

27. Martin A, Leone L, Castagliuolo I, Di Mario F, Naccarato R. When do patients want to know about their inflammatory bowel disease? Ital J Gastroenterol 1992;24:477-80.

28. Mayberry JF, Morris JS, Calcraft B, Rhodes J. Information assessment by patients of a booklet on Crohn's disease. Public Health 1985;99:239-42.

29. Probert CS, Mayberry JF. Inflammatory bowel disease: Patients' expectations in the 1990s. J R Soc Med 1991;84:131-2.

30. Rees JEP, Mayberry JF, Calcraft B. What the patient wants to know about Crohn's disease. J Clin Gastroenterol 1983;5:221-2.

31. Scholmerich J, Sedlak P, Hoppe-Seyler P, Gerok W. The information needs and fears of patients with inflammatory bowel disease. Hepatogastroenterology 1987;34:182-5.

32. Moser G, Tillinger W, Sachs G, et al. Disease-related worries and concerns: A study on out-patients with inflammatory bowel disease. Eur J Gastroenterol Hepatol 1995;7:853-8.

33. Brown SA. Studies of educational interventions and outcomes in diabetic adults: A meta-analysis revisited. Patient Educ Couns 1990;16:189-215.

34. Devine EC. Meta-analysis of the effects of psychoeducational care in adults with asthma. Res Nurs Health 1996;19:367-76.

35. Devine EC, Pearcy J. Meta-analysis of the effects of psychoeducational care in adults with chronic obstructive pulmonary disease. Patient Educ Couns 1996;29:167-78.

36. Devine EC, Reifschneider E. A meta-analysis of the effects of psychoeducational care in adults with hypertension. Nurs Res 1995;44:237-45.

37. Devine EC, Westlake SK. The effects of psychoeducational care in adults with cancer: Meta-analysis of 116 studies. Oncol Nurs Forum 1995;22;9:1369-81.

38. Gibson PG, Coughlan J, Wilson AJ, et al. Self-management education and regular practitioner review for adults with asthma. Cochrane Database Syst Rev 2000;(2):CD001117.

39. Mazzuca SA. Does patient education in chronic disease have therapeutic value? J Chronic Dis 1982;35:521-9.

40. Roter DL, Hall JA, Merisca R, Nordstrom B, Cretin D, Svarstad B. Effectiveness of interventions to improve patient compliance: A meta-analysis. Med Care 1998;36:1138-61.

41. Quan H, Present JW, Sutherland LR. Evaluation of educational programs in inflammatory bowel disease. Inflamm Bowel Dis 2003;6:356-62.

42. Schreiber S, Hamling J, Wedel S, et al. Efficacy of patient education in chronic inflammatory bowel disease in a prospective controlled multicenter trial. Gastroenterology 1999;116:A815. (Abst)

43. Robinson A, Thompson DG, Wilkin D. Guided self-management in ulcerative colitis: Better treatment and more efficient use of health services. Gastroenterology 1999;116:A91. (Abst)

44. Kennedy A, Robinson A, Hann M, Thompson D, Wilkin D; North-West Region Gastrointestinal Research Group. A clusterrandomised controlled trial of a patient-centred guidebook for patients with ulcerative colitis: Effect on knowledge, anxiety and quality of life. Health Soc Care Community 2003;11:64-72.

45. Larsson K, Sundberg Hjelm M, Karlbom U, Nordin K, Anderberg UM, Loof L. A group-based patient education programme for high-anxiety patients with Crohn's disease for ulcerative colitis. Scand J Gastroenterol 2003;38:763-9. 
46. Borgaonkar MR, Townson G, Donnelly M, Irvine EJ. Providing disease-related information worsens health-related quality of life in inflammatory bowel disease. Inflamm Bowel Dis 2002;8:264-9.

47. Irvine EJ, Feagan B, Rochon J, et al. Quality of life: A valid and reliable measure of therapeutic efficacy in the treatments of inflammatory bowel disease. Canadian Crohn's Relapse Prevention Trial Study Group. Gastroenterology 1994;106:287-96.

48. Yoshida EM. The Crohn's Disease Activity Index, its derivatives and the Inflammatory Bowel Disease Questionnaire: A review of instruments to assess Crohn's disease. Can J Gastroenterol 1999;13:65-73.

49. Best WR, Becktel JM, Singleton JW, Kern F Jr. Development of a Crohn's disease activity index. Gastroenterology 1976;70:439-44.

50. Best WR, Becktel JM, Singleton JW. Rederived values of the eight coefficients of the Crohn's disease activity index (CDAI). Gastroenterology 1979;77:843-6.

51. Seo M, Okada M, Yao T, Okabe N, Maeda K, Oh K. Evaluation of disease activity in patients with moderately active ulcerative colitis: Comparisons between a new activity index and Truelove and Witts' classification. Am J Gastroenterol 1995;90:1759-63.

52. Seo M, Okada M, Yao T, Ueki M, Arima S, Okumura M. An index of disease activity in patients with ulcerative colitis. Am J Gastroenterol 1992;87:971-6.
53. Hjortswang H, Strom M, Almeida RT, Almer S. Evaluation of the RFIPC, a disease-specific health-related quality of life questionnaire, in Swedish patients with ulcerative colitis. Scand J Gastroenterol 1997;32:1235-40.

54. Zernike W, Henderson A. Evaluating the effectiveness of two teaching strategies for patients diagnosed with hypertension. J Clin Nurs 1998;7:37-44.

55. Theis SL, Johnson JH. Strategies for teaching patients: A meta-analysis. Clin Nurse Spec 1995;9:100-5, 120.

56. Estey A, Musseau A, Keehn L. Patient's understanding of health information: A multihospital comparison. Patient Educ Couns 1994;24:73-8.

57. Hawkey GM, Hawkey CJ. Effect of information leaflets on knowledge in patients with gastrointestinal diseases. Gut 1989;30:1641-6.

58. Smart H, Mayberry J, Calcraft B, Morris JS, Rhodes J. Effect of information booklet on patients' anxiety levels and consultation rates in Crohn's disease. Public Health 1986;100:184-6.

59. Verma S, Tsai HH, Giaffer MH. Does better disease-related education improve quality of life? A survey of IBD patients. Dig Dis Sci 2001;46:865-9.

60. Pekkala E, Merinder L. Psychoeducation for schizophrenia. The Cochrane Library, Issue 4. Oxford: Update Software 2000. 


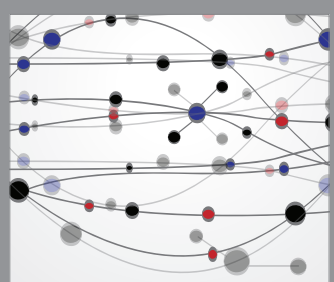

The Scientific World Journal
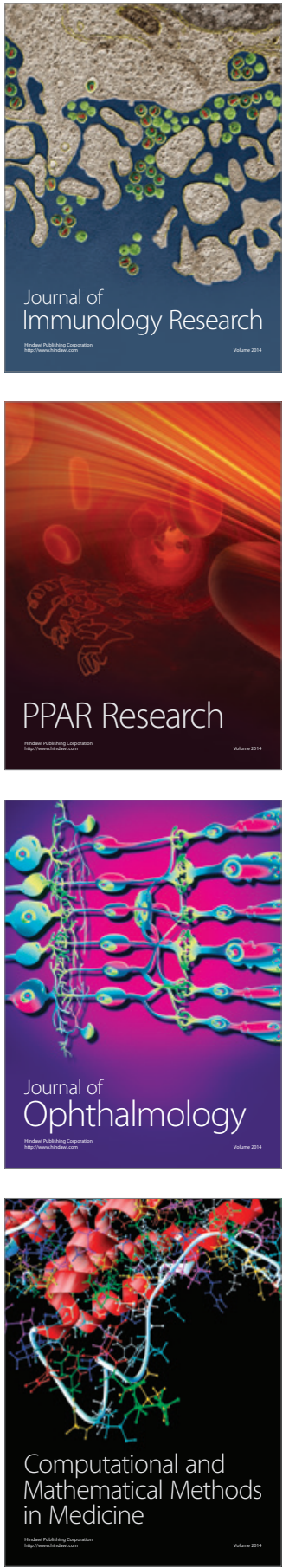



Gastroenterology Research and Practice



\section{Hindawi}

Submit your manuscripts at

http://www.hindawi.com
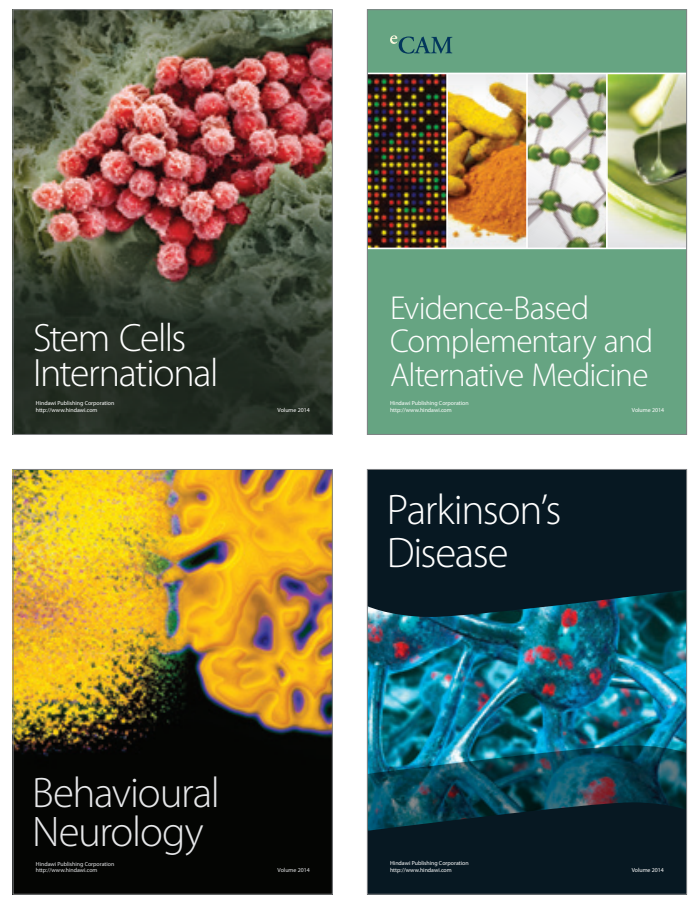


Disease Markers
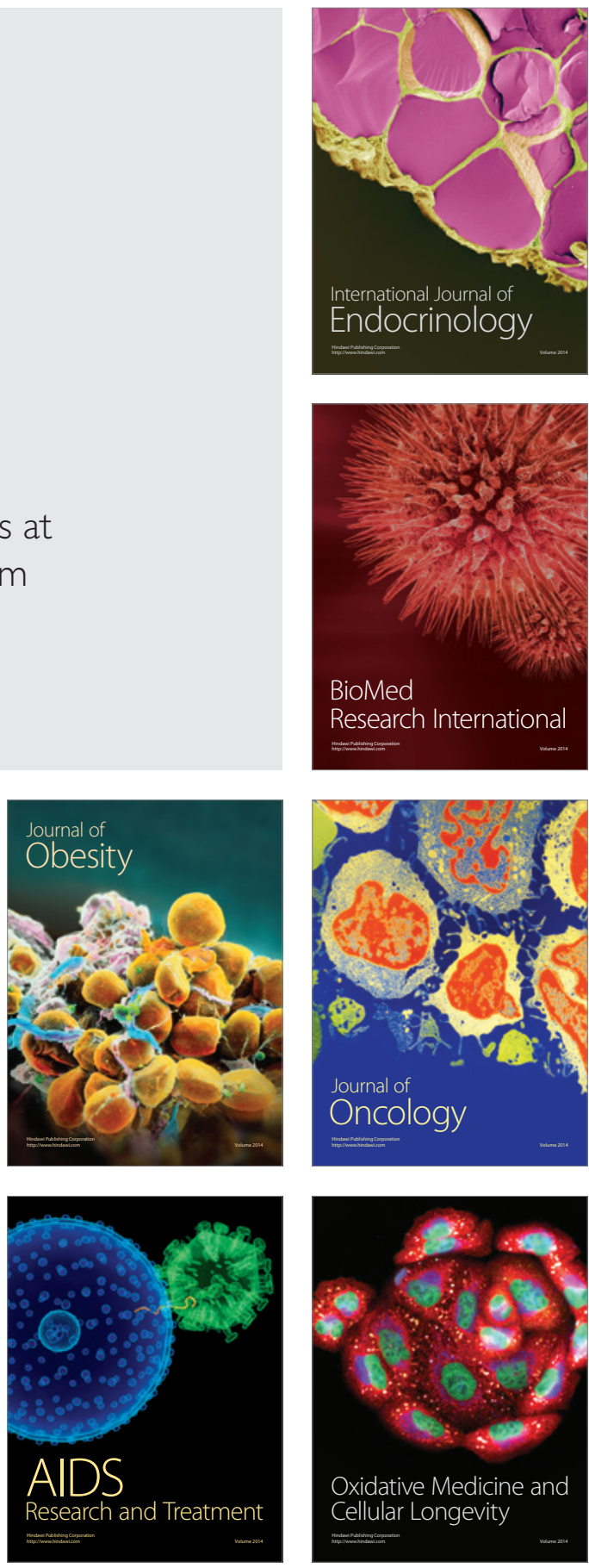